Georgia State University

ScholarWorks @ Georgia State University

Computer Information Systems Faculty

Publications

Department of Computer Information Systems

2011

\title{
Comparing e-Learning Tools' Success: The Case of Instructor-Student Interactive vs. Self-paced Tools
}

\author{
J.J. Po-An Hsieh \\ Georgia State University, jjhsieh@gsu.edu \\ Vincent Cho \\ Hong Kong Polytechnic University, vincent.cho@polyu.edu.hk
}

Follow this and additional works at: https://scholarworks.gsu.edu/cis_facpub

Part of the Management Information Systems Commons

\section{Recommended Citation \\ Hsieh, J.J. Po-An and Cho, Vincent, "Comparing e-Learning Tools' Success: The Case of Instructor-Student Interactive vs. Self-paced Tools" (2011). Computer Information Systems Faculty Publications. 17. \\ https://scholarworks.gsu.edu/cis_facpub/17}

This Article is brought to you for free and open access by the Department of Computer Information Systems at ScholarWorks @ Georgia State University. It has been accepted for inclusion in Computer Information Systems Faculty Publications by an authorized administrator of ScholarWorks @ Georgia State University. For more information, please contact scholarworks@gsu.edu. 


\title{
Comparing e-Learning Tools' Success: The Case of Instructor-Student Interactive vs. Self-paced Tools
}

\begin{abstract}
E-learning tools have profoundly transformed modern pedagogical approaches. Vendors provide different types of systems, such as self-paced (SP) and instructor-student interactive (ISI) elearning tools. Although both types of tools represent promising solutions to facilitate the learning process, it is important to theoretically identify a framework to evaluate the success of these tools and assess whether one type of tool is more effective than another. Toward this end, we (1) propose a model to evaluate e-learning tools' success by extending and contextualizing Seddon's information systems (IS) success model for the e-learning environment and (2) formulate four hypotheses to predict the differences in the success factors between SP and ISI tools. We test the model and hypotheses using data from 783 students across seven higher education institutions in Hong Kong. The results support the proposed e-learning tool success model and three of the four hypotheses. ISI tools outperform SP tools in terms of system quality, perceived usefulness, satisfaction, and learning outcome.
\end{abstract}

\section{Keywords:}

e-learning tool, IS success model, multi-group comparison, media richness

\section{Acknowledgments:}

We are grateful to two anonymous referees for their constructive comments on an earlier version of this paper. The first author acknowledges the financial support from the Hong Kong Research Grant Council (General Research Fund \#B-Q17P). The second author acknowledges the financial support from the Hong Kong Polytechnic University under grant number U040. 


\section{Comparing e-Learning Tool Success: \\ The Case of Instructor-Student Interactive vs. Self-paced Tools}

\section{INTRODUCTION}

Advances in computer technology in the past few decades have significantly transformed contemporary teaching approaches. Systems providers have developed different types of e-learning tools that can make the learning process easier and enhance its outcome. Higher education institutions are taking advantage of these elearning tools to design and offer new opportunities for teaching and learning (e.g., Casini, 2003; Goffe \& Sosin, 2005; Martins \& Kellermanns, 2004; Zhang, 2004; Seo \& Woo, 2010; Cho et al., 2009). According to a recent report of International Data Corporation (IDC), the global e-learning market was around USD 17.2 billion in 2008 and was expected to continue growing. Given that much is at stake, evaluating the effectiveness of e-learning tools is important. As such, this paper examines the relative success of self-paced (SP) and instructor-student interactive (ISI) tools, which are the two most applied e-learning tools.

SP e-learning tools refer to computer or online learning programs that include informational resources of a course topic and assessment mechanisms for selfevaluation (Bretz \& Johnson, 2000). Students can learn at their own pace and at such locations as their homes, residence halls, laboratories, or workplaces. For example, Holt (2007) set up free online experiments for learning economic concepts available to students anytime and anywhere. Off-the-shelf software programs such as language learning or professional knowledge development are now available in retail stores; consumers can simply buy and install these programs on their own. Many higher education institutions also equip their student centers with self-directed e-learning programs in order for students to learn at their own initiative. These types of learning tools are consistent with contemporary education theories that emphasize on selfpaced and self-directed learning (Dalgarno, 2001).

Alternatively, ISI e-learning tools, which are similar to web-based course management systems, refer to digital technologies that facilitate distribution and exchange of information between instructors and students aside from their classroom interaction (Martins \& Kellemanns, 2004). Increasingly more higher education institutions are deploying such ISI e-learning tools as Moodle, SAKAI, Lotus Learning Space, Blackboard, WebCT (which has been acquired by Blackboard in 
2005), and the like, to support the interaction between students and instructors aside from their classroom activities. Through ISI tools, students can interact with instructors via such media as e-mail, whiteboard, live chatting, and video conferencing; they can also download available course materials online. This mix of traditional learning with the support of ISI e-learning tools can be effective. Some researchers have contended that this hybrid mode is better than either the pure online or strictly in-classroom approach because a wider variety of learning tools can be used while retaining face-to-face contact and lectures (Simon et al. 1996; Brown \& Liedholm, 2002, 2004; Riffell \& Sibley, 2005; Vernadakis et al., 2011).

There are theoretical arguments, as well as empirical evidence, endorsing the value of e-learning tools. Although both types of tools represent promising solutions to facilitate the learning process, the implementation of either type of tools demands substantial resources such as money, time, and human effort. The time students invest in using these systems also represents opportunity cost that requires justification. Therefore, it is imperative to theoretically identify a framework to evaluate the effectiveness of these e-learning tools and ascertain whether one type of tool is more effective than another. As such, we follow a theoretically grounded approach to (1) propose an extended Seddon's (1997) information systems (IS) success model for elearning tools and (2) investigate the key differences (i.e., information quality, perceived usefulness, learning outcome, and satisfaction) between SP and ISI elearning tools that determine the success of e-learning tools. Thus, we focus on the following research questions:

RQ1: What is the IS success model for e-learning tools?

RQ2: Between Self-paced and Instructor-Student Interactive e-learning tools, which one is more effective?

\section{THEORETICAL BACKGROUND}

\section{IS Success Model for e-Learning Tools}

The evaluation of the success of IS has been a major issue in IS research. The models proposed by DeLone and McLean (1992) (D\&M) and Seddon (1997) have received the most attention (Rai et al., 2002). A primary difference between the two models is the inclusion or exclusion of the system usage construct. Whereas D\&M 
treated usage as a success variable, Seddon contended that usage does not reflect success if the context is not entirely voluntary; Seddon replaced usage with perceived usefulness as proxies for net benefits from use, arguing that perceived usefulness could reflect system success even in a mandatory context. A comparative study by Rai et al. (2002) revealed that the Seddon model performs slightly better than the D\&M model, supporting Seddon's conceptualization of three construct categories: (1) information and system quality, (2) general perceptual measure of net benefits from IS usage, and (3) IS behavior. With this backdrop, in this research, we evaluate the success of the two modes of e-learning tools using the theoretical framework of Seddon's IS success model.

According to Seddon's IS success model, system quality (SQ) and information quality (IQ) are the two variables that depict the quality of an IS. These two constructs influence the generally perceived net benefits derived from usage, namely, perceived usefulness (PU) and satisfaction (SAT). PU and SAT may also be subject to influence by other measures of net benefits at the individual, organizational, and/or societal levels. Given our focus on e-learning tools' success at the individual level, we include learning outcome (LO) as the individual net benefit derived from system usage. In addition, we include behavioral intention (BI) for future use to capture the behavioral aspect of Seddon's framework.

Figure 1 illustrates the nomological network of six constructs. All the relationships are specified based on Seddon's success model, except for the path from PU to BI. We include this additional path for the following reasons. First, the question of whether a technology is useful is a rational utilitarian consideration for initial and continued usage. PU is perhaps one of the most consistent determinants of IS usage across different innovation stages (Legris et al., 2003; Venkatesh \& Davis, 2000). According to the expectancy confirmation theory, during the post-adoptive stage, continued intention to use will be influenced by actual satisfaction and PU (Bhattacherjee, 2001; Bhattacherjee \& Premkumar, 2004); empirical evidence has also revealed consistent support for this causal link from PU to BI (Bhattacherjee, 2001; Bhattacherjee \& Premkumar, 2004; Hong et al. 2006). If PU reflects the benefit derived from prior usage, and BI concerns future usage, arguing for a directional relationship from PU to $\mathrm{BI}$ is reasonable. Given the aforementioned theoretical reasoning and empirical evidence, we extend Seddon's model by adding this additional path in the nomological network. 
Insert Figure 1 here

\section{Related Education and Communication Theories}

To evaluate the success of one type of e-learning tool in relation to another, we need to understand whether a specific type of e-learning tool can effectively support the learning process. In this regard, it is important to determine whether the tools can provide feedback and continuously refine the learning process; accommodate individual characteristics, needs, learning styles, and learning pace; and deliver highquality information through an appropriate medium to create a sense of personal touch and support. Thus, we review the relevant learning and communication theories about feedback, individualization, media richness, and social presence to deduce the relative effectiveness of SP and ISI e-learning tools theoretically.

The individual learning process can be viewed as a continuous loop that includes experiencing, acting, reflecting, and evaluating, where feedback is an important mechanism that can greatly enhance learning effectiveness (Kolb, 1984; Lewin, 1951). Education scholars have long recognized that feedback can effectively improve students' learning performance (Mory, 2003). Feedback may include messages that confirm accurate causal relationships between stimuli and responses, corrects errors, reinforces correct answers, and even stimulates students' motivation for further engagement and higher intellectual development (Mory, 2003; Scott, 2002). Feedback constitutes the basis for the continuous process of goal-directed action, as well as the evaluation of the outcomes of these actions, serving as a powerful mechanism to improve learning effectiveness (Lewin, 1951). Based on the current advances in technology, both SP and ISI e-learning tools can help students obtain feedback about their learning status and/or task performance.

Aside from feedback, the individualization of the pedagogical procedures also affects learning performance (Federico, 1991). Individual learners differ in their backgrounds, learning styles, pace of learning, traits, and needs (Daudelin, 1996; Ramsey, 2005; Schipper, 1999). Given that such learning activities as experiencing and reflecting are individualized phenomenon, procedures that can consider individual differences can understandably enhance learning effectiveness (Kolb, 1984). Empirical evidence suggests that students learn more efficiently when pedagogical 
procedures are adaptable to individual differences (Federico, 1991). However, learning contexts that ignore individual distinctions may enable some students, if not all, to perceive learning "as a challenge, hard, or distasteful”" (Gregorc, 1984). A metaanalysis of studies over a 10-year period involving 3,181 students further revealed that teaching that adapts to individual differences leads to higher performance (Dunn et al., 1995).

E-learning tools can be considered a digital medium that facilitates information exchange between knowledge sources (instructors) and their recipients (students). In this case, the richness of the different media may affect students' learning effectiveness. The media richness theory (MRT) contends that the effectiveness of information processing is determined by the fit between task equivocality (or ambiguity) and media richness. Equivocality refers to the extent to which information is unclear and lends itself to multiple interpretations (Daft \& Weick, 1986). Task equivocality usually emanates from the lack of understanding between communicators with respect to the task of interest. Based on the MRT, the richer the medium, the more it has the following attributes: 1) immediate feedback, 2) number of cues involved (i.e., body language, facial expression, and tone of voice), 3) message personalization, and 4) natural languages; the richer the medium, the more likely it is to reduce equivocality. Therefore, media richness is referred to as the ability of the media to "overcome different frames of reference or clarify ambiguous issues to change understanding in a timely manner" (Daft \& Lengel, 1984, 1986). Although tasks with higher equivocality demand media with higher richness, media with lower richness may sometimes be good enough for processing well-understood messages or simple concepts (Daft \& Lengel, 1986; Trevino et al., 1987). According to Fulk et al. (1995), social interaction among situated actors facilitates the creation of shared meanings that help define the uses and outcomes of communication technologies. Moreover, Huang et al. (1996; 1998) found that social construction, which refers to social interaction among communicators to exchange different viewpoints and understand each other's preferences, mindsets, needs, and frames of references, can help communicators communicate more effectively. They showed that social construction among communicators could transform a lean computer-mediated communication medium into a rich one, such that the performance of the lean medium approximates the performance of face-to-face communication (Huang et al., 1996). 
Similar to the MRT, the social presence theory posits that media are chosen for specific types of interaction and for how well they fit the information requirements of a task (Short et al., 1976). Media differ in social presence or the degree to which a medium permits users to experience others as being psychologically present (Fulk et al., 1987). Empirical studies show that different media (e.g., e-mail vs. fax) possess different degrees of information richness and social presence (Simon et al., 1996; Gefen \& Straub, 1997). Socially present media have potentially higher ability to transfer information that is beyond pure text-based messages, such as facial expression, direction of sight, posture, dress, and nonverbal cues (Short et al., 1976). Media such as video or voice conferencing, although not as much "socially present" as face-to-face meetings, are high in social presence, whereas interaction with software packages has been found to be relatively low in social presence.

\section{Research Hypotheses}

The extended Seddon IS success model (Figure 1) provides a framework to identify the key factors for evaluating the success of e-learning tools. Based on the previously discussed learning and communication theories, we develop four hypotheses to predict if one type of e-learning tool will be more successful than another in terms of IQ, PU, performance outcome, and $\mathrm{SAT}^{1}$.

Although SP and ISI e-learning tools are both electronically mediated, they are different in terms of media richness and social presence. In the case of SP tools, information exchange occurs between students and software programs. Most programs interact with students on an instant basis, whereas some offer a natural language interface. Some programs permit a certain degree of individualization to accommodate differences in personal backgrounds and learning statuses (Marline \& Niss, 1982; Sadde \& Kira, 2004). Nevertheless, although SP tools may incorporate multimedia course contents, they still do not involve human instructors in the learning process. This type of e-learning tool involves less human cues, resulting in lower social presence.

\footnotetext{
${ }^{1}$ Note that we do not focus on theorizing the difference in SQ between different types of e-learning tools. The SQ of e-learning tools will, to a large extent, be determined by the designers and manufacturers of the systems, which is beyond the theoretical scope of our discussion.
} 
In ISI e-learning tools, interaction takes place between instructors and students. This type of electronically facilitated learning, aside from traditional interaction in a classroom, allows communication between students and instructors through e-mail, whiteboard, live chatting, or video conferencing. Such a variety of communication media allows for a wider range of information richness and social presence. For instance, live chatting provides instant feedback in natural language; whiteboard can provide instant elaboration through voice communication and graphic collaboration; and video conferencing presents facial expressions further. Although e-mail does not work on a synchronous basis, it provides natural language in written format. In general, ISI tools offer more natural languages and social cues, if not more immediate feedback. As a result, information from ISI tools, rather than SP tools, is more likely to help students deal with the equivocality or ambiguity experienced in the learning process.

In the context of ISI e-learning tools, the interaction occurring in classroom lectures and communication via ISI e-learning tools can facilitate social construction between students and their instructors. As discussed earlier, social construction between communicators can positively augment the effect of communication media (Huang et al., 1996). In this regard, students can learn more about their instructors' explicit and implicit perspectives, mindsets, and frames of references, collectively equipping the students to interpret better and digest the information and knowledge offered by the instructors using the ISI tools. Thus, the social construction allowed in the case of the ISI tools, in relation to the SP tools where no social interaction occurs, can enhance students' evaluation of the quality of information offered.

Moreover, ISI tools can offer a higher level of individualization than SP tools. During the learning process, students normally experience difficulty in understanding the ideas and concepts being taught. ISI e-learning tools allow individual students to specify their unique problems and enable instructors to provide their responses to students' needs personally. In contrast, SP e-learning tools can only provide feedback based on answers already programmed. Unless the designers of the programs can exhaustively include all the possible situations and answers, today's available SP programs in the market suggest that SP tools are less likely to customize their information as well as their ISI tools. Based on the above discussions, we believe that ISI e-learning tools have higher IQ than SP tools. 


\section{H1: Information quality of ISI e-learning tools is higher than that of SP e-} learning tools.

SP e-learning tools allow students to progress at their own speed. Today, SP elearning tools are equipped with self-assessment mechanisms for students to evaluate themselves and obtain instant feedback. However, compared with the feedback from ISI tools, computer-generated feedback from SP tools is more mechanical and generic. Aside from the more customizable information provided by instructors, ISI tools are likely to supplement the traditional classroom learning on the feedback loop where students can ask questions pertaining to their learning activities at any time through the Internet. Studies have shown that instructors can interact differently with different students (Frankel \& Swanson, 2002). Through their interaction with students, instructors may gradually understand more about students' unique learning status and needs, enabling more customized communication approaches. Thus, students may find ISI e-learning tools to be more useful than SP tools. From the students' perspective, they may also develop better understanding about their instructors through this refined communication process. Such enhanced mutual understanding, as a result of the ongoing social construction (Huang et al. 1996) between students and instructors, can likely strengthen students' overall perception about the usefulness of ISI tools.

Individual learning takes place in a variety of situations. Compared with SP elearning tools, the customizability, interactivity, and flexibility embedded in ISI tools are more likely to foster a higher level of PU among students.

\section{H2: The perceived usefulness of ISI e-learning tools is higher than that of SP e-learning tools.}

In the two types of e-learning tools, feedback from instructors to students in the ISI mode can be refined continuously, whereas SP tools can provide feedback with only limited refinement. As discussed earlier, during interaction with an SP e-learning tool, the response or feedback from the program is pre-programmed and is not likely to be adequately exhaustive for all possible scenarios. Such type of feedback may work for simple tasks but not necessarily for relatively more complex situations. For instance, during a multiple choice exercise, a student may choose a wrong answer. The SP learning tool instantly gives the explanation on why an answer is incorrect and 
then provides the correct answer. However, if the student has further inquiry and wants more elaborated explanations, the SP tool is unlikely to fulfill such requests.

In contrast, through ISI e-learning tools, students may receive more in-depth and individualized response/feedback from their instructors. Using the aforementioned example, instructors can elaborate the explanations and help the student consider further how to apply the concept in different contexts. Through interaction, instructors can also offer personalized comments based on their understanding about the student. The instructors' feedback and comments also help students develop a better understanding of the course objectives. As a result, students can adjust and regulate their learning activities more effectively towards achieving these objectives. Students can even be motivated to develop their competency further in the subject area (Mory, 2003). Arguably, the continuously personalized feedback also allows ISI tools to be perceived as more useful and with higher IQ than the SP tools. According to Zhang et al. (2006) and Abdous and Yen (2010), e-learning tools would help to improve both learning satisfaction and the assessment score which is a measure on learning outcome. In this study, learning outcome (LO) refers to the perceived grade increment after using the chosen e-learning tool. Moreover, many researchers believe that continuous interactivity between the knowledge source and the recipient is a vital element in the educational process; recent research suggests that interactivity strongly affects the learning outcome (Wang et al., 2007; Arbaugh, 2005; Swan, 2003; Wagner, 1997). Compared with SP e-learning tools, the better refined and individualized information and messages from instructors via ISI e-learning tools can help students achieve higher LO.

\section{H3: Learning outcomes of ISI e-learning tools are higher than those of SP e-learning tools.}

Satisfaction with a technology reflects individuals' overall feeling after interacting with the technology. This overall affect captures such perceptions as IQ, PU, and performance outcomes (Seddon, 1997). As we argue for higher perceptions of these three dimensions in ISI tools than in SP tools, expecting students to have higher SAT with ISI than with SP tools is reasonable. Furthermore, one major weakness of SP tools lies in the lack of human social presence (Short et al., 1976). In the context of ISI e-learning tools, a student "feels" the support from the instructor, representing a social capital that takes care of the emotional and psychological 
stresses the student experiences during the learning process. In contrast, SP e-learning tools have no such abilities. Encouragement and recognition are easily delivered through the instructor-student interaction using e-learning tools (Peltier \& Drago, 2003; Scott, 2002). Moreover, as instructors typically represent the authority of the course knowledge, the student may feel that information through ISI e-learning tools is a more reliable and trustworthy means of learning than that through SP tools. Therefore, we expect that learner satisfaction with ISI e-learning tools is higher than that with SP e-learning tools.

H4: Learner satisfaction with instructor-student interactive e-learning tools will be higher than learner satisfaction with self-paced $e$ learning tools.

\section{Control Variables}

Previous studies have reported that individual IS perceptions and behaviors may differ across such personal factors as gender, education, and age (e.g., Agarwal \& Prasad, 1999; Frankel, 1990; Gefen \& Straub, 1997; Venkatesh \& Morris, 2000; Venkatesh, 2003). Hence, these factors are controlled in this study.

\section{METHODOLOGY}

\section{Data Collection}

Given the research objectives, a survey approach is adequate. A survey instrument was developed to collect quantitative data for model and hypothesis testing. Recommendations from five IS experts and professors were incorporated to improve the instrument. A pilot study was then conducted to evaluate the instrument further. Questionnaires were distributed to 100 randomly selected higher education students in Hong Kong, and minor modifications were made based on the feedback received. An exploratory factor analysis was performed to preliminarily evaluate the measurement properties. Table 1 list the factor loadings and reliabilities of the constructs in the pilot study. Appendix A lists the measurement items in the survey adapted from existing scales for the context of e-learning tools and operationalized in a way similar to prior research. Six items were adapted from Rai et al. (2002) and Wang (2003) for IQ. Following the approach by Doll and Torkzadeh (1998) and Rai et al. (2002), 
perceived ease of use (PEOU) was used to represent SQ. Items for PEOU (four items) and PU (four items) were adapted from Davis (1989). SAT was measured by four items from Oliver (1980) and Spreng and Chiou (2002). LO was measured by a single item asking if using the e-learning tool has increased the grade of the subject. While it would be ideal to trace participants' pre and post assessment, our cross-sectional research design only permits us to measure participants' perceived grade increment as LO evaluation, which is consistent with the approached used is by Marline \& Niss (1982) and Piccoli et al. (2001). Following Seddon's logic, items of net benefit constructs (i.e., PU, SAT, and LO) were presented to capture the benefits derived from using e-learning systems rather than expectations about benefits from future use. Finally, BI for future use, which consists of four items, was measured using the scale recommended by Ajzen and Fishbein (1980). All constructs were operationalized with five-point Likert scales, ranging from (1) "strongly disagree" to (5) "strongly agree."

Insert Table 1 here

According to Bloom's taxonomy (Bloom et al., 1956), the learning outcome achieved with e-learning tools could depend on the nature, complexity and scope of the learning domain. In order to make the SP and the ISI e-learning tools comparable, it is preferable to investigate university-level subjects as university-level subjects which usually involve much complexity that allows for students to approach these subjects via different tools from different perspectives. For instance, when learning Group Decision Making, ISI tools can assist students to comprehend the analytical techniques for group decision making and then apply the techniques in various case studies; instructors can then evaluate the results of these exercise. Alternatively, there are also SP tools that incorporate self-learning content about the analytical techniques for group decision making as well as simulation functionalities that allows students to experiment with the analytical techniques in different hypothetical scenarios; the tools can also evaluate if students have properly applied the techniques. In other words, ISI and SP tools, though different in many aspects, both permit students to develop their knowledge about learning subjects.

The instrument was designed to first ask respondents to choose only one type of e-learning tool (either SP or ISI) that they used the most and then answer the 
questionnaires with regard to the chosen tool(s). Both the SP and ISI tools were explained and illustrated well in the questionnaire. The questions always stressed "the chosen e-learning tool" to remind the respondents to focus on their perception on the chosen e-learning tool.

The official survey was conducted by distributing the questionnaires to students randomly selected in common areas, libraries, and canteens of seven higher education institutions in Hong Kong, namely the Chinese University of Hong Kong, the City University of Hong Kong, the Hong Kong Baptist University, the Hong Kong Institute of Education, the Hong Kong University of Science and Technology, Lingnan University, and the University of Hong Kong, at different time slots. The Open University of Hong Kong, which mandates students to use some self-learning packages that are supported by a learning platform, was excluded because our goal was to study acceptance of e-learning tools on a voluntary basis. Students were asked if they have the experience of using e-learning tools. For those with positive response, they were invited to complete the questionnaire. In order to gather more returns and to show our sincerity in conducting the survey, a donation of HK\$1 was made to a charity organization for every completed survey. We also explained to the respondents the purposes of the survey so as to motivate them to fill in the questionnaires on the spot. The confidentiality of the results was stressed. Nevertheless, some respondents left the questionnaires blank and the response rate was $70 \%$. To minimize data entry errors, all the collected data were checked for consistency. All the duplicate responses and all the responses that had too many missing values were removed. After excluding incomplete responses, the number of effective respondents for SP and ISI learning tools were 445 and 293, respectively. The profile of the respondents on SP and ISI e-learning tools are shown in Table 2.

Insert Table 2 here

\section{ANALYSES AND RESULTS}

We applied structural equation modeling using AMOS 6.0 to conduct a series of data analyses. These analyses include the measurement model fit, structural model fit, 
multi-group measurement invariance, and mean comparison of latent constructs across groups.

\section{Measurement Models}

Measurement properties of all constructs were first evaluated with the confirmatory factor analysis (CFA) for each group independently. After deleting three items with low loading, the resulting fit indices suggest an acceptable fit. As shown in Table 3, all indices are above their criterion levels. Hu and Bentler (1999) proposed a strict combination rule: (1) SRMR $<0.08$ and (2) either CFI $>0.95$ or RMSEA $<0.06$. Instead of evaluating each index independently, this rule has the advantage of controlling types I and II errors simultaneously. The results in Table 3 show that the indices of both models comply with this combinational rule, further supporting the measurement model fit. Descriptive statistics of the constructs are listed in Table 4.

Insert Table 3 here

Insert Table 4 here

Internal consistency and convergent validity were further evaluated by examining Cronbach's alpha, composite reliability, and average variance extracted (AVE) of each construct (Table 5). The values of Cronbach's alpha and composite reliabilities were all higher than the recommended 0.707 (Nunnally, 1978), and the AVE values were all above 0.50 (Fornell \& Larcker, 1981).

Insert Table 5 here

The value of AVE of every construct is higher than its squared correlations with other constructs (Table 5), supporting discriminant validity (Fornell \& Larcker, 1981). Discriminant validity was further examined by testing whether the correlations between pairs of constructs are significantly different from unity (Gefen et al., 1997). Chi-square of the unconstrained CFA is generally lower than any possible union of any two constructs (see Appendix B-1 for SP e-learning tools and B-2 for ISI tools). The results of the above two analyses jointly support discriminant validity. 


\section{Structural Models}

After the establishment of the measurement models for each group, we evaluated the structural model fit for each group independently. As shown in Table 6, the indices of both structural models comply with $\mathrm{Hu}$ and Bentler's (1999) combinational rule, providing evidence of good model fit. Figures 2 and 3 illustrate the structural models of SP and ISI tools, respectively.

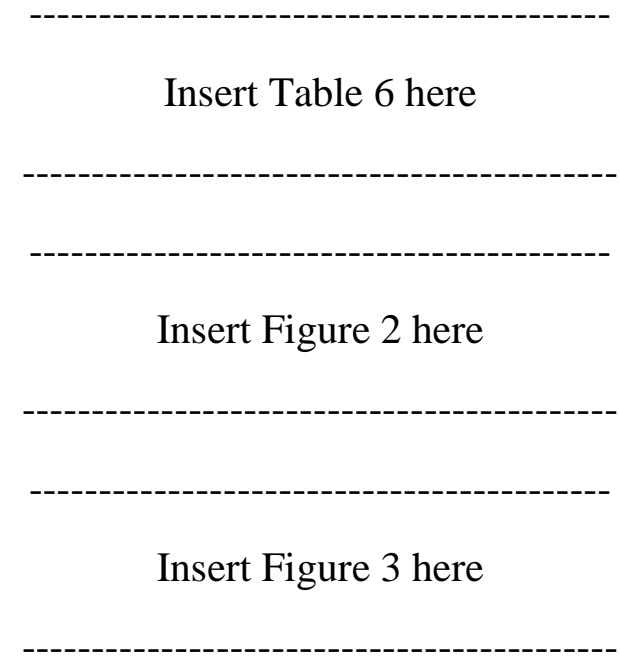

Common method bias: We conducted the Harmon one-factor analysis suggested by Podsakoff and Organ (1986) to check the existence of a common method bias. For both types of e-learning tools, a factor analysis combining every variable in the research framework did not detect a single factor explaining the majority of covariance. The results of the structural models also showed different degrees of significance for path coefficients. The above evidence collectively suggests that common method bias is not a serious concern in this study.

\section{Measurement Invariance Analysis and Mean Comparison}

To evaluate the appropriateness of comparing the means of the multi-item constructs across the two groups, we applied the multi-group measurement invariance analysis (Doll et al., 1998; Steenkamp \& Baumgartner, 1998). Using the AMOS 6.0 software, we performed configural, metric, and scalar invariance analyses to evaluate if the measurement models are invariant between the two types of e-learning tools. Configural invariance means that the item loading patterns across groups are congeneric. When modeling configural invariance, no restrictions are imposed on the metrics between groups (Doll et al., 1998; Hsieh et al., 2008). Metric invariance 
depends on whether items have equal loadings across groups. Item loadings are constrained to be the same across groups when modeling metric invariance. Scalar invariance checks the consistency between cross-group differences in latent construct means and cross-group differences in observed means. Scalar invariance is evaluated by constraining the intercepts of measures to be the same across groups.

These three invariance models assume a hierarchical order: configural invariance precedes metrics invariance, and metric invariance precedes scalar invariance. A comparison of latent constructs means across groups is not meaningful unless scalar invariance, the most complex among the three, is supported (Doll et al., 1998; Hsieh et al., forthcoming; Steenkamp \& Baumgartner, 1998). As these invariance models are nested, the difference between any two nested models can be assessed by evaluating the changes in CFI. If the change in CFI between two nested (e.g., configural and metric) models is smaller than the suggested threshold of 0.01 (Cheung \& Rensvold, 2002), then a more complex invariance is supported.

We first applied the analytical procedure described above to assess the measurement invariance across the two groups. Configural invariance analyses showed acceptable measurement model fit and revealed the pattern of item loadings to be congeneric across the groups (Table 7). From configural to metric and then to scalar invariance, CFI decreased from 0.972 to 0.971 and then to 0.968 . The changes in CFI of the nested models were all smaller than the recommended 0.01 (Cheung \& Rensvold, 2002). Thus, scalar invariance was established across the groups.

Insert Table 7 here

Under scalar invariance, latent construct means were compared by constraining them at zero for ISI tools and allowing the construct means of SP tools to be estimated freely. If an estimated construct mean of SP tools is significantly different from zero, this pair of construct means is different across the two groups (MacKenzie \& Spreng, 1992). Six pairs of multi-item constructs were found to be different between the two types of e-learning tools (Table 8). ISI tools had significantly higher SQ, IQ, PU, LO, and SAT, as well as BI.

Insert Table 8 here 
Finally, we conducted further analyses to examine alternative explanations for the mean difference results detected earlier because of individual differences in gender, education, or age (e.g., Agarwal \& Prasad, 1999; Venkatesh \& Morris, 2000; Venkatesh et al., 2003). Following the aforementioned mean comparison procedure, we split the sample of each e-learning tool into different subgroups to evaluate the potential effect of personal factors on core IS success constructs ${ }^{2}$. Specifically, we compared the construct means between the SP and ISI male respondents for evaluating gender effect; for education, we compared the SP and ISI subjects whose education level was undergraduate; and for age, we compared the SP and ISI respondents who were 25 years old or younger. The results of the three comparisons (Table 9) reveal similar differences to those between the overall SP and ISI groups with one exception: there was no mean difference in IQ between the SP and ISI respondents whose education attainment was undergraduate and between the SP and ISI respondents whose age was 25 or younger. Thus, the detected mean difference in IQ across SP and ISI tools is inconclusive.

In short, the above results collectively suggest that, consistent with our expectation, perceived usefulness, learning outcome, and learner satisfaction were higher for instructor-student interactive e-learning tools than for self-paced e-learning tools, thereby supporting $\mathrm{H} 2, \mathrm{H} 3$, and $\mathrm{H} 4$, respectively. However, information quality of instructor-student interactive e-learning tools was not necessarily higher than information quality of the self-paced e-learning tools. H1 was therefore not supported.

\section{Insert Table 9 here}

\footnotetext{
${ }^{2}$ We split the overall sample to create subgroups according to subjects' age, education, or gender. However, due to the limited sample size in some subgroups, we were not able to conduct all the possible comparisons exhaustively. Take gender, for instance. We compared the latent construct means between the subgroups of SP and ISI male respondents. Nevertheless, as the sample sizes of ISI female respondents $(\mathrm{N}=114)$, age $>25(\mathrm{~N}=109)$ and postgraduate $(\mathrm{N}=97)$ were too small for the SEM analysis, we were constrained to compare the construct means between the SP and ISI male subjects, for age $<=25$ and for undergraduate only. Fortunately, for age, education, and gender, there were sufficient sample sizes for at least one subgroup comparison across SP and ISI tools (see Table 9).
} 


\section{DISCUSSIONS}

The results reveal several interesting findings among the two types of e-learning tools. First, the proposed extended Seddon IS model fit both types of tools well. The key constructs in the research framework were also comparable across the groups. Finally, ISI e-learning tools dominated the SP tools in almost all aspects of the success model. In the following section, we focus our discussion on the key findings for each research question.

RQ1: The first research question attempts to identify the framework in evaluating the success of e-learning tools. The results of the structural model supported the proposed model. First, the fit indices of the structural models for both elearning tools complied with the required thresholds (Table 6). The models also accounted for more than half of the variance in the dependent variables. In particular, in the SP tools, the structural model (Figure 2) successfully explained 45\%, 50\%, and $60 \%$ of variance in PU, SAT, and BI, respectively. For ISI tools, the model (Figure 3) explained $58 \%, 65 \%$, and $61 \%$ of variance in PU, SAT, and BI, respectively.

Congruent with Seddon's model, PU was affected by IQ, SQ, and LO. SAT was determined by IQ, PU, and LO for both types of e-learning tools and by SQ (i.e., PEOU) only for SP tools.

Furthermore, as anticipated, for both SP and ISI tools, BI for future use was influenced by SAT and PU. In terms of individual differences, female subjects were marginally more likely to continue using SP tools (Figure 2), and people with higher education level were marginally more likely to continue their use of ISI tools (Figure 3). To evaluate the additional explanatory power provided by this path from PU to BI, we tested further the original Seddon model where PU does not affect BI. A comparison of the original model and the extended Seddon model suggests that the addition of this path significantly increased by $5 \%$ in the explained variance of BI.

RQ2: The second research question examines whether one type of e-learning tools is superior to the other type for students' learning. As pointed out by Doll et al. (1998), most extant IS research has compared results across different groups (e.g., applications) without verifying if the conceptualization of a construct is invariant across groups. This practice assumes that a construct is perceived invariantly by different groups. In this regard, if different groups indeed perceive the construct differently, such direct comparison would be meaningless and could lead to flawed 
conclusions. As shown in Table 7, the measurement models of the two types of elearning tools are scalarly invariant, thus allowing the comparison of the latent construct mean across groups (Doll et al., 1998; Steenkamp \& Baumgartner, 1998).

A comparison of the IS success constructs between the two modes of e-learning tools strongly suggests that ISI learning tools were superior to SP e-learning tools in many aspects of system success (Table 8$)^{3}$. Consistent with our predictions, ISI tools facilitated better LO and made students perceive the systems as offering higher usefulness and SAT than SP tools. The ad hoc analysis further suggests that students perceived the SQ (i.e., ease of use) of ISI to be higher than that of SP tools. Given the overwhelming success of ISI over SP tools, it is not surprising that students had higher intention to use ISI than SP tools in the future.

Although SP tools can respond to students on a real-time basis and also allow students to move at their own pace most of the time, ISI tools involve more natural languages, social cues, individualized feedback, elaborated information, support from human instructors, and social construction between students and instructors. The most important difference between the two modes of e-learning tools is perhaps the agents who instruct students: human instructors versus software programs. Although both modes of e-learning are mediated by information technologies, human instructors are more likely to communicate with students using natural language and to be perceived as social support by students. More importantly, although both types of tools can provide feedback to facilitate students' learning process, human instructors are more likely to be able to personalize feedback and elaborate relevant information based on students' unique backgrounds, personality, and learning status. The higher interactivity between students and instructors also allows the development of shared social construction and foster a more refined learning process, thereby leading to higher performance. As a whole, these reasons can contribute to the superior learning experiences facilitated by ISI tools.

In summary, the proposed extended Seddon IS success model demonstrates good model fit and successfully explains a significant portion of variances in the dependent variables for both types of tools. The added path from PU to BI offers additional

\footnotetext{
${ }^{3}$ Note that because there were no mean differences in information quality across the corresponding subgroups of SP and ISI tools, the difference in information quality between SP and ISI tools must be investigated further in future research.
} 
authority in explaining students' intention to use specific e-learning tools continually. The results also reveal significant differences in SQ, LO, PU, and SAT between SP and ISI e-learning tools. Although students had positive perceptions for both types of tools (Table 4, all construct means > 3), ISI dominated SP tools in almost every dimension of IS success. As a result, students had higher intention to continue using ISI than SP tools.

For researchers, this study represents an important step towards understanding e-learning tools' effectiveness using a theoretically grounded approach. While the extended Seddon model was withheld for both groups of e-learning tools, the important between-group differences in the success factors were theoretically deduced and empirically tested. Whereas the differences between success factors for SP and ISI e-learning tools explain the discrepancies in their relative effectiveness, the structural model uncovers which interventions are required to achieve higher overall SAT and intention to continue the use of the technology. Thus, from the standpoint of e-learning tools' success, this study constitutes a valuable contribution to the theoretical development of e-learning IS success.

For practitioners, our results offer insights that can help educators better design their programs to enhance students' learning experiences. E-learning tools offer advantages to overcome logistics issues such as time and place, allowing students to engage in learning activities more autonomously. The evolution of IT also induces many innovations in pedagogical practices. With ISI e-learning tools, instructors can distribute their materials to students in various formats for different purposes. Although interaction can still take place in classroom, it can also occur via e-mail, chat room, whiteboard, forum, and video conferencing. As different media have different levels of media richness, the array of media available in ISI e-learning tools can be used for tasks or problems according to their levels of complexity. Students can also use SP e-learning tools to support their knowledge development. With SP tools, students can make progress according to their personal needs and receive immediate feedback to adjust their learning activities.

\section{LIMITATIONS}

As is the case with all empirical research, this investigation also has several limitations. A notable weakness lies in the cross-sectional research design, where all measurement items were collected at the same time. Given that the investigated constructs are not supposed to remain unchanged over time, this research method may not fully capture the dynamics of the extended IS success model. Thus, this constraint limits the extent to which causality can be inferred. To address the above issues, future research should consider employing multi-methods and longitudinal research designs. A longitudinal study combining qualitative and quantitative data would enable a process-oriented perspective that cannot be achieved using a variance-based approach such as the one employed in this study.

In addition, the IS success model proposed by Seddon (1997) suggests that system quality (measured as ease of use in this study) and information quality both have direct impacts on perceived usefulness and users satisfaction, but no direct impact on net benefits for individual users (measured as perceived learning outcome in this study). While our research model is theoretically informed by Seddon's model, 
his model implies that system quality and information quality may indirectly affect net benefit for individual users through, first, user satisfaction, then expectation about benefits of future IS use, and finally IS use which is our focus in this study. Alternatively, will system quality and information quality have direct effect on learning outcomes which are the main reason for using the e-learning tools from the students' perspective? And, how the learning outcomes in turn affect students' satisfaction, perceived usefulness and future use? Although examining these plausible alternative causal chains are beyond the scope of this study, we encourage interested scholars to conduct studies for further investigation.

Furthermore, given the intricacy involved in students' e-learning activities, factors such as students' learning styles, nature of the studied subject, motivation (Durresi and de Marco, 2006; Pudichery, 2003; Matsuo et al. 2008), fluid intelligence (Barton, 1999), working memory (van Merrienboer and Ayres, 2005; Medina, 2008), spatial ability (Hannafin, et al. 2008; Duesbury and O'Neil, 1996), and instructors' teaching philosophy may all potentially account for the variance of learner's satisfaction of using e-learning tools. Instead of measuring learning outcome as perceived grade increment after using an e-learning tool, future studies should also consider actual learning performance as more objective measure (Alavi, Yoo, \& Vogel, 1997; Leidner \& Fuller, 1997; Piccoli et al., 2001; Vogel, Davison, \& Shroff, 2001). Moreover, the nature, complexity, and scope of the learning domain, task and learning outcomes (e.g. Blooms learning outcomes) being achieved from the use of each type of e-learning tool should be controlled in the future. For instance, social interaction may be more appropriate for achieving higher cognitive learning outcomes such as analysis, synthesis and evaluation; whereas self-paced instructions may be used more to teach lower level cognitive outcomes such as knowledge recall and comprehension. Although this study emphasizes the key constructs in IS success literature, future research should investigate the possible moderating effect of related factors on IS success factors as well as on the relationships between these factors.

\section{CONCLUSION}

This study empirically supports the extended Seddon IS success model for e-learning tools. Drawing upon communication and education theories, this study also compares the critical success factors of SP and ISI e-learning tools. The findings suggest that 
ISI e-learning tools outperform SP tools in terms of SQ, PU, LO, and SAT. Students also have higher intention of continuing the usage of ISI tools than SP tools. This study represents an important step towards developing our theoretical understanding of the relative success between different types of e-learning tools and extending the theoretical framework of IS success. The findings in this study also provides insights for educators on which variables/conditions exert the greatest influence on student satisfaction and future intent, and which variables should be given great priority when developing instructional interventions.

\section{REFERENCES}

Abdous M. \& Yen C.J. (2010). A predictive study of learner satisfaction and outcomes in face-to-face, satellite broadcast, and live video-streaming learning environments. Internet and Higher Education, 13, 248 - 257.

Agarwal, R. \& Prasad, J. (1999). Are individual differences germane to the acceptance of new information technologies? Decision Sciences, 30 (2), 361391.

Ajzen, I. \& Fishbein, M. (1980). Understanding Attitudes and Predicting Social Behaviour, Prentice-Hall, New Jersey.

Alavi, M., Yoo, Y. \& Vogel, E. R. (1997). Using information technology to add value to management education. Academy of Management Journal, 40 (6), 1310 1333.

Arbaugh, J.B. (2005). Is there an optimal design for online MBA courses? Academy of Management Learning and Education, 4 (2), 135-149.

Barolli, L. \& Keyama, A., Durresi, A \& de Marco G. (2006). A web-based e-learning system for increasing study efficiency by stimulating learner's motivation. Information Systems Frontier, 8, 297 - 306.

Barton, J.W. (1999). Fluid Intelligence and use of Cognitive Learning Strategies. PhD Dissertation, The University of Texas at Austin.

Bhattacherjee, A. (2001). Understanding information systems continuance: an expectation-confirmation model. MIS Quarterly, 25 (3), 351-370.

Bhattacherjee, A. \& Premkumar, G. (2004). Understanding changes in belief and attitude toward information technology usage: A theoretical model and longitudinal test. MIS Quarterly, 28 (2), 229-254.

Bloom, B.S. (Ed.), Engelhart, M.D., Furst, E.J., Hill, W.H., \& Krathwohl, D.R. (1956). Taxonomy of Educational $\backslash$ Objectives: the Classification of Educational Goals. Handbook 1: Cognitive domain. New York: David Mckay.

Bretz, R. \& Johnson, L. (2000). An innovative pedagogy for teaching and evaluating 
computer literacy. Information Technology and Management, 1 (4), 283 - 292. Brown, B.W. \& Liedholm, C.E. (2002). Can Web courses replace the classroom in principles of microeconomics? American Economic Review, 92 (2), 444 - 448.

Brown, B.W. \& Liedholm, C.E. (2004). Designing online course materials based on student preferences in using learning resources. Presentation at the Allied Social Science Association, San Diego, http://www.msu.edu/ brownb/brownliedholm_aea_2004.pdf

Casini, M. (2003). The automatic control telelab: a user-friendly interface for distance learning. IEEE Transactions on Education, 46 (2), 252 - 257.

Cheung, G.W. \& Rensvold, R.B. (2002). Evaluating goodness-of-fit indexes for testing measurement invariance. Structural Equation Modeling, 9 (2), 233-255.

Cho, V., Cheng, T.C.E., \& Lai, J. (2009). The role of perceived user-interface design in continued usage intention of self-paced e-learning tools. Computers \& Education, 53, 2, 216 - 227.

Daft, R.L. \& Lengel, R. (1984). Information Richness: A new approach to managerial behaviour and organization design, in: Research in organizational behaviour, B. Staw and L. Cummings (eds.), 191 - 233.

Daft, R.L. \& Lengel, R.H. (1986). Organizational information requirements, media richness and structural design. Management Science, 32 (5), 554-571.

Daft, R.L. \& Weick, K.E. (1986). Toward a model of organizations as interpretation systems. The Academy of Management Review, 9 (2), 284 - 293.

Dalgarno, B. (2001). Technologies supporting highly interactive learning resources on the web: an analysis. Journal of Interactive Learning Research, 12(3), 153 171.

Daudelin, M.W. (1996). Learning from Experience through Reflection. Organizational Dynamics, 24 (3), 36-48.

Davis, F. (1989). Perceived usefulness, perceived ease of use and user acceptance of information technology. MIS Quarterly, 13 (3), 319 - 340.

DeLone, W.H. \& McLean, E.R. (1992). Information systems success: the quest for the dependent variable. Information Systems Research, 3 (1), 60-95.

Doll, W.J. Hendrickson, A. \& Deng, X. (1998). Using Davis's perceived usefulness and ease-of-use instruments for decision making: A confirmatory and multigroup invariance analysis. Decision Sciences, 29 (4), 839-869.

Dunn, R., Griggs, S.A., Olson, J. \& Beasly, M. (1995). A meta-analytic validation of the Dunn and Dunn model of learning style preferences. Journal of Educational Research, 88 (6), 353 - 362.

Duesbury, R.T. \& O’Neil H.F.O. (1996). Effect of type of practice in a computeraided design environment in visualizing three-dimensional objects from two- 
dimensional orthographic projections. Journal of Applied Psychology, 81 (3), $249-260$.

Federico, P.A. (1991). Student cognitive attributes and performance in a computermanaged instructional setting, in: R. Dillon, J. Pellegrino, (Eds.), Instruction: Theoretical and applied perspectives, Praeger, New York, 16 - 46.

Fornell, C. \& Larcker, D.F. (1981). Evaluating structural equation models with unobservable variables and measurement error. Journal of Marketing Research, 18 (1), 39-50.

Frankel, K.A. (1990). Women and Computing. Communications of the ACM, 33 (11), $34-45$.

Frankel, R. \& Swanson, S.R. (2002). The impact of faculty-student interactions on teaching behavior: an investigation of perceived student encounter orientation, interactive confidence, and interactive practice. Journal of Education for Business, 78 (2), 85 - 91.

Fulk, J., Schmitz, J. \& Ryu, D. (1995). Cognitive elements in the social construction of communication technology. Management Communications Quarterly, 8 (3), $259-288$.

Fulk, J., Steinfield, C.W., Schmitz, J. \& Power, G.J. (1987). A social information processing model of media use in organizations. Communication Research, 14 (5), $520-552$.

Gefen, D. \& Straub D.W. (1997). Gender differences in the perception and use of email: an extension to the technology acceptance model. MIS Quarterly, 21 (4), $389-400$.

Gefen, D., Karahanna, E. \& Straub, D.W. (2003) Trust and TAM in online shopping: An integrated model. MIS Quarterly, 27 (1), 51-90.

Goffe, W.L. \& Sosin, K. (2005). Teaching with technology: may you live in interesting times. Journal of Economic Education, 36(3), 278 - 291.

Gregorc, A.F. (1984). Style as a symptom: a phenomenological perspective. Theory and Practice, 23 (1), 51 - 55.

Hannafin, R.D., Truxaw, M.P., Vermillion, J.R. \& Liu Y. (2008). Effects of spatial ability and instructional program on geometry achievement. The Journal of Educational Research, 101 (3), 148 - 157.

Holt, C. (2007). Computer programs for classroom games. retrieved from http://www.people.virginia.edu/ cah2k/programs.html.

Hong, S., Thong, J. \& Tam, K.Y. (2006). Understanding continued information technology usage behavior: A comparison of three models in the context of mobile internet. Decision Support Systems, 42 (3), 1819 - 1834. 
Hsieh, J.J., Rai, A. \& Keil, M. (2008). Understanding digital inequality: comparing continued use behavioral models of the socio-economically advantaged and disadvantaged. MIS Quarterly, 32 (1), 97 - 126.

Hu, L. \& Bentler, P. (1999). Cutoff criteria for fit indexes in covariance structural analysis: Coventional criteria versus new alternatives, Structural Equation Modeling, 6(1), 1 - 55.

Huang, W., Watson, R.T. \& Wei, K.K. (1998). Can a lean e-mail medium be used for rich communication? A psychological perspective. European Journal of Information Systems, 7(4), 269 - 275.

Huang, W., Wei, K.K., Watson, R.T., Lim, L.H. \& Bostrom, R. (1996). Transforming a learn CMC medium into a rich one: an empirical investigation in small groups, Proceedings of the Seventeenth Annual International Conference on Information Systems, USA, 265-277.

IDC, (2009). Worldwide and U.S. Corporate eLearning 2009 - 2013 Forecast: cost savings and effectiveness drive slow market. International Data Corporation.

Kocharekar, R.A. (2001). A pattern emerges. Intelligent Enterprise, 4 (13), 18-19

Kolb, D.A. (1984). Experiential Learning, Prentice Hall, New Jersey.

Lee, J.K. (2009). The effects of self-regulate learning strategies and system satisfaction regarding learner's performance in e-learning environment. Journal of Instructional Pedagogies. 1, $30-45$.

Legris, P., Ingham, J. \& Collerette, P. (2003). Why do people use information technology? A critical review of the technology acceptance model. Information \& Management, 40 (3), 191-204.

Leidner, D. E. \& Fuller, M. (1997). Improving student learning of conceptual information: GSS supported collaborative learning vs. individual constructive learning. Decision Support Systems, 20 (2), 149-163.

Lewin, K. (1951). Field Theory in Social Science: Selected Theoretical Papers, Harper and Row, New York.

MacKenzie, S.B. \& Spreng, R.A. (1992). How does motivation moderate the impact of central and peripheral processing on brand attitude and intentions? Journal of Consumer Research, 18 (4), 519-529.

Marline, J.W. \& Niss, J.N. (1982). The advanced learning system, a computer managed, self-paced system of instruction: an application in principles of economics. Journal of Economic Education, 12 (2), 26 - 39.

Martins, L.L. \& Kellermanns, F.W. (2004). A model of business school students' acceptance of a web-based course management system. Academy of Management Learning and Education, 3 (1), 7 - 26. 
Matsuo, K., Barolli, L., Xhafa, F., Koyama, A., \& Durresi, A. (2008). New functions for stimulating learners' motivation in a web-based e-learning system. International Journal of Distance Education Technologies, 6 (4), 34 - 49.

Medina A. D. (2008). Concurrent verbalization, task complexity, and working memory: Effects on L2 learning in a computerized task. Ph.D. Dissertation, Georgetown University, 341 pages.

Mory, E.H. (2003). Feedback research revisited. In D.H. Jonassen (ed.), Handbook of research for educational communications and technology, 2nd Edition, Lawrence Erlbaum, Mahwah, NJ, 745-783.

Nunnally, J. (1978). Psychometric Theory, McGraw-Hill, New York, NY.

Oliver, R.L. (1980). A cognitive model for the antecedents and consequences of satisfaction. Journal of Marketing Research, 17 (4), 460 - 469.

Peltier, J.W., Drago, W. \& Schibrowsky, J.A. (2003). Virtual communities and the assessment of online marketing education. Journal of Marketing Education, 25 (3), $260-276$.

Piccoli, G., Ahmad, R. \& Ives, B. (2001). Web-based virtual learning environments: A research framework and a preliminary assessment of effectiveness in basic IT skills training. MIS Quarterly, 25 (4), 401-426.

Podsakoff, P.M. \& Organ, D.W. (1986). Self reports in organizational research: problems and prospects. Journal of Management, 12 (4), 531-544.

Pudichery, J.P. (2003). The role of web technology in education. Proceedings of the Academy of Educational Leadership, 8 (2), Las Vegas.

Rai, A., Lang, S.S. \& Welker, R.B. (2002). Assessing the validity of IS success models: An empirical test and theoretical analysis. Information Systems Research, 13 (1), 50-69.

Ramsey, C. (2005). Narrative from learning in reflection to learning in performance. Management learning, 36 (2), 219 - 235.

Riffell, S., \& Sibley, D. (2005). Using web-based instruction to improve large undergraduate biology courses: an evaluation of a hybrid course format. Computers \& Education, 44, 3, 217 - 235.

Ritzhaupt, A.D., Gomes, N.D. \& Barron, A.E. (2008). The effects of time-compressed audio and verbal redundancy on learner performance and satisfaction. Computers in Human Behavior, 24, 5, 2434-2445.

Saade, R.G. \& Kira, D. (2004). Effectiveness of an interactive application to assist learning: a test case. Journal of Information Systems Education, 15 (4), 357 363.

Schipper, F. (1999). Phenomenology and the reflective practitioner. Management Learning, 30 (4), $473-485$. 
Scott, J.L. (2002). Stimulating awareness of actual learning processes. Journal of the Operational Research Society, 53 (1), 2 - 10.

Seddon, P.B. (1997). A respecification and extension of the DeLone and McLean model of IS success. Information Systems Research, 8 (3), 240-253.

Seo, Y.J., \& Woo, H. (2010). The identification, implementation, and evaluation of critical user interface design features of computer assisted instruction programs in mathematics for students with learning disabilities. Computers \& Education, 55, 1, 363 - 377.

Short, J. Williams, E. \& Christie, B. (1976). The social psychology of telecommunications, Wiley, London.

Simon, S.J., Grover, V., Teng, J.T.C. \& Whitcomb, K. (1996). The relationship of information system training methods and cognitive ability to end-user satisfaction, comprehension, and skill transfer: a longitudinal field study. Information Systems Research, 7 (4), 466 - 490.

Spreng, R.A. \& Chiou, J.S. (2002). A cross-cultural assessment of the satisfaction formation process. European Journal of Marketing, 36(7/8), 829 - 839.

Steenkamp, J. \& Baumgartner, H. (1998). Assessing measurement invariance in cross-national consumer research. Journal of Consumer Research, 25 (1), 7890.

Straub, D.W. (1994). The effect of culture on IT diffusion: e-mail and fax in Japan and the US. Information Systems Research, 5 (1), 23 - 47.

Swan, K. (2003). Learning effectiveness: what the research tells us. In Bourne, J., and Moore, J.C., (eds.). Elements of quality online education: practice and direction, Sloan Center for Online Education, Needham, MA, 13 - 45.

Trevino, L.K., Lengel, R.H. \& Daft, R.L. (1987). Media symbolism and media choice in organizations: A symbolic interactionist perspective. Communication Research. 14 (5), 653-669.

Van Dijk, J. \& Hacker, K. (2003). The digital divide as a complex and dynamic phenomenon. The Information Society, 19 (4), 315-326.

Van Merriënboer, J.J.G., \& Ayres, P. (2005). Research on cognitive load theory and Its design implications for e-Learning. Educational Technology Research and Development, 53 (3), 5 - 13.

Venkatesh, V. \& Davis, F.D. (2000). A theoretical extension of the technology acceptance model: four longitudinal field studies. Management Science, 46 (2), 186-204.

Venkatesh, V. \& Morris, M.G. (2000). Why don't men ever stop to ask for directions? gender, social influence, and their role in technology acceptance and usage behavior. MIS Quarterly, 24 (1), 115-139. 
Venkatesh, V., Morris, M.G., Davis, G.B. \& Davis, F.D. (2003). User acceptance of information technology: toward a unified view. MIS Quarterly, 27 (3), 425 450.

Vernadakis N., Antoniou, P., Giannousi, M., Zetou, E., \& Kioumourtzoglou, E. (2011). Comparing hybrid learning with traditional approaches on learning the Microsoft Office Power Point 2003 program in tertiary education. Computers \& Education, 56, 188 - 199.

Vogel, D. R., Davison, R. M. \& Shroff, R. H. (2001). Socio-cultural learning: a perspective on GSS-enabled global education. Communications of the AIS, 7, $1-39$.

Wagner, E.D. (1997). Interactivity: from agents to outcomes, in: E. Cyrs (Ed.), Teaching and learning at a distance: What it takes to effectively design, deliver, and evaluate programs, Jossey-Bass Publishers, San Francisco, 19-26.

Waldrop, M.M. (1997). How the chess was won. MIT's Technology Review, 100 (6), 33-36.

Wang, Y.S. (2003). Assessment of learner satisfaction with asynchronous electronic learning systems. Information \& Management, 41 (1), 75-86.

Wang Y.S., Wang, H.Y. \& Shee, D.Y. (2007). Measuring e-learning systems success in an organizational context: Scale development and validation. Computers in Human Behavior, 23, 1792 -1808.

Zhang, D. (2004). Virtual mentor and the lab system - toward building an interactive, personalized, and intelligent e-learning environment. The Journal of Computer Information Systems, 44 (3), 35 - 43.

Zheng, D., Zhou, L., Briggs, R.O., \& Nunamaker, J.F. (2006). Instructional video in e-learning: assessing the impact of interactive video on learning effectiveness. Information \& Management, 43, 15 - 27. 


\section{Appendix A: Survey Items}

\begin{tabular}{|l|}
\hline Information Quality (IQ) \\
\hline The chosen e-learning tool provides sufficient information for my study. \\
\hline The chosen e-learning tool provides accurate information for my study. \\
\hline The chosen e-learning tool provides up-to-date information for my study. (Dropped) \\
\hline The chosen e-learning tool provides useful information for my study. \\
\hline The chosen e-learning tool provides relevant information for my study. \\
\hline Overall information provided by the chosen e-learning tool is satisfactory. \\
\hline
\end{tabular}

\begin{tabular}{|l|}
\hline System Quality (proxy by Perceived Ease of Use, PEOU) \\
\hline Use of the chosen e-learning tool is simple. \\
\hline $\begin{array}{l}\text { I have no trouble in using the chosen e-learning tool to perform the task that I } \\
\text { needed. (Dropped) }\end{array}$ \\
\hline The chosen e-learning tool is easy to comprehend. \\
\hline As a whole, the chosen e-learning tool is easy to use. \\
\hline
\end{tabular}

\begin{tabular}{|l|}
\hline Perceived Usefulness (PU) \\
\hline Use of the chosen e-learning tool enabled me to accomplish tasks more quickly. \\
\hline Use of the chosen e-learning tool improved the quality of my tasks. \\
\hline Use of the chosen e-learning tool enhanced the effectiveness of my tasks. \\
\hline As a whole, the chosen e-learning tool is useful to me. \\
\hline
\end{tabular}

\begin{tabular}{|l|}
\hline Satisfaction (SAT) \\
\hline $\begin{array}{l}\text { Using the chosen e-learning tool would give me a better opportunity to explore the } \\
\text { subject. (Dropped) }\end{array}$ \\
\hline $\begin{array}{l}\text { Using the chosen e-learning tool would give me a sense of self-control of my } \\
\text { learning pace. }\end{array}$ \\
\hline My decision to use the chosen e-learning tool was a wise one. \\
\hline In general, using the chosen e-learning tool would give me a sense of satisfaction. \\
\hline
\end{tabular}

\begin{tabular}{|l|}
\hline Learning Outcome (LO) \\
\hline The chosen e-learning tool improves my grade on the subject. \\
\hline
\end{tabular}

\begin{tabular}{|l|}
\hline Behavioral Intention to Use in the future (BI) \\
\hline I will use the chosen e-learning tool in the future. \\
\hline I intend to use the chosen e-learning tool more in the chosen subject. \\
\hline I intend to use the chosen e-learning tool more in other subjects. \\
\hline I intend to increase my use of the chosen e-learning tool in the future. \\
\hline
\end{tabular}




\section{Appendix B-1: Pair-wise Discriminant Analyses (Self-}

\section{Paced E-learning)}

\begin{tabular}{|l|c|c|c|}
\hline Model & $\chi 2$ & d.f. & $\begin{array}{l}\text { p-value of } \\
\chi 2 \text { test }\end{array}$ \\
\hline Original & 247.872 & 142 & \\
\hline \multicolumn{1}{|c|}{ Pair-wise Combination } & & & \\
\hline Intention to Use + Information Quality & 456.292 & 143 & 0.00 \\
\hline Intention to Use + Perceived Ease of Use (SQ) & 437.225 & 143 & 0.00 \\
\hline Intention to Use + Perceived Usefulness & 408.247 & 143 & 0.00 \\
\hline Intention to Use + Satisfaction & 421.932 & 143 & 0.00 \\
\hline Information Quality + Perceived Ease of Use & 481.757 & 143 & 0.00 \\
\hline Information Quality + Perceived Usefulness & 439.281 & 143 & 0.00 \\
\hline Information Quality + Satisfaction & 494.370 & 143 & 0.00 \\
\hline Perceived Ease of Use + Perceived Usefulness & 461.738 & 143 & 0.00 \\
\hline Perceived Ease of Use + Satisfaction & 479.327 & 143 & 0.00 \\
\hline Perceived Usefulness + Satisfaction & 456.058 & 143 & 0.00 \\
\hline
\end{tabular}

\section{Appendix B-2: Pair-wise Discriminant Analyses (Instructor-}

\section{Student Interactive Mode)}

\begin{tabular}{|l|c|c|c|}
\hline Model & $\chi 2$ & d.f. & $\begin{array}{l}\text { p-value of } \\
\chi 2 \text { test }\end{array}$ \\
\hline Original & 240.701 & 142 & \\
\hline \multicolumn{1}{|c|}{ Pair-wise Combination } & & & \\
\hline Intention to Use + Information Quality & 278.523 & 143 & 0.00 \\
\hline Intention to Use + Perceived Ease of Use (SQ) & 388.868 & 143 & 0.00 \\
\hline Intention to Use + Perceived Usefulness & 363.799 & 143 & 0.00 \\
\hline Intention to Use + Satisfaction & 341.061 & 143 & 0.00 \\
\hline Information Quality + Perceived Ease of Use & 375.753 & 143 & 0.00 \\
\hline Information Quality + Perceived Usefulness & 353.786 & 143 & 0.00 \\
\hline Information Quality + Satisfaction & 357.512 & 143 & 0.00 \\
\hline Perceived Ease of Use + Perceived Usefulness & 361.236 & 143 & 0.00 \\
\hline Perceived Ease of Use + Satisfaction & 374.483 & 143 & 0.00 \\
\hline Perceived Usefulness + Satisfaction & 338.398 & 143 & 0.00 \\
\hline
\end{tabular}


Figure 1: Research Framework - Extended Seddon IS Success Model

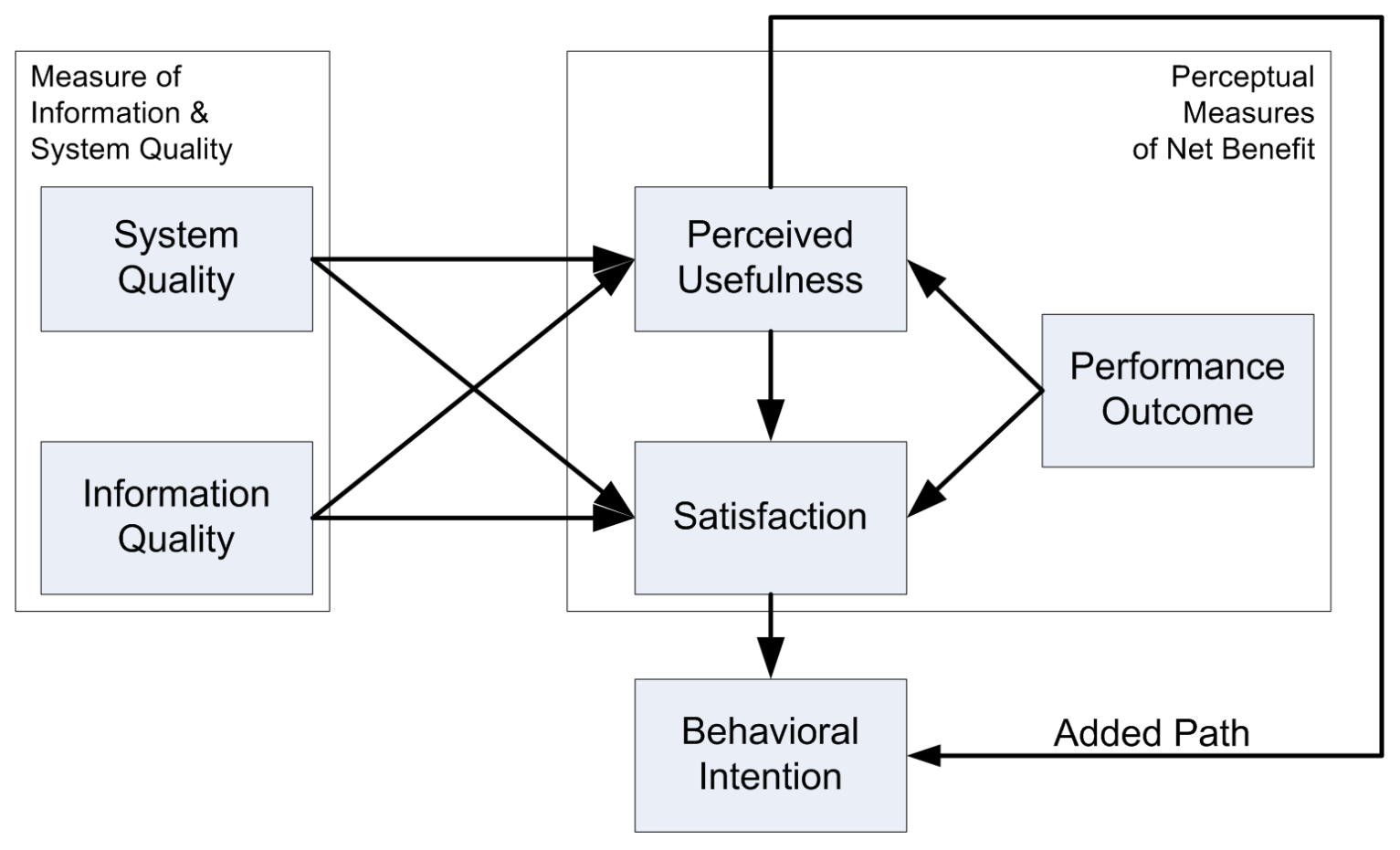


Figure 2: Structural Model of Self-Paced Tools

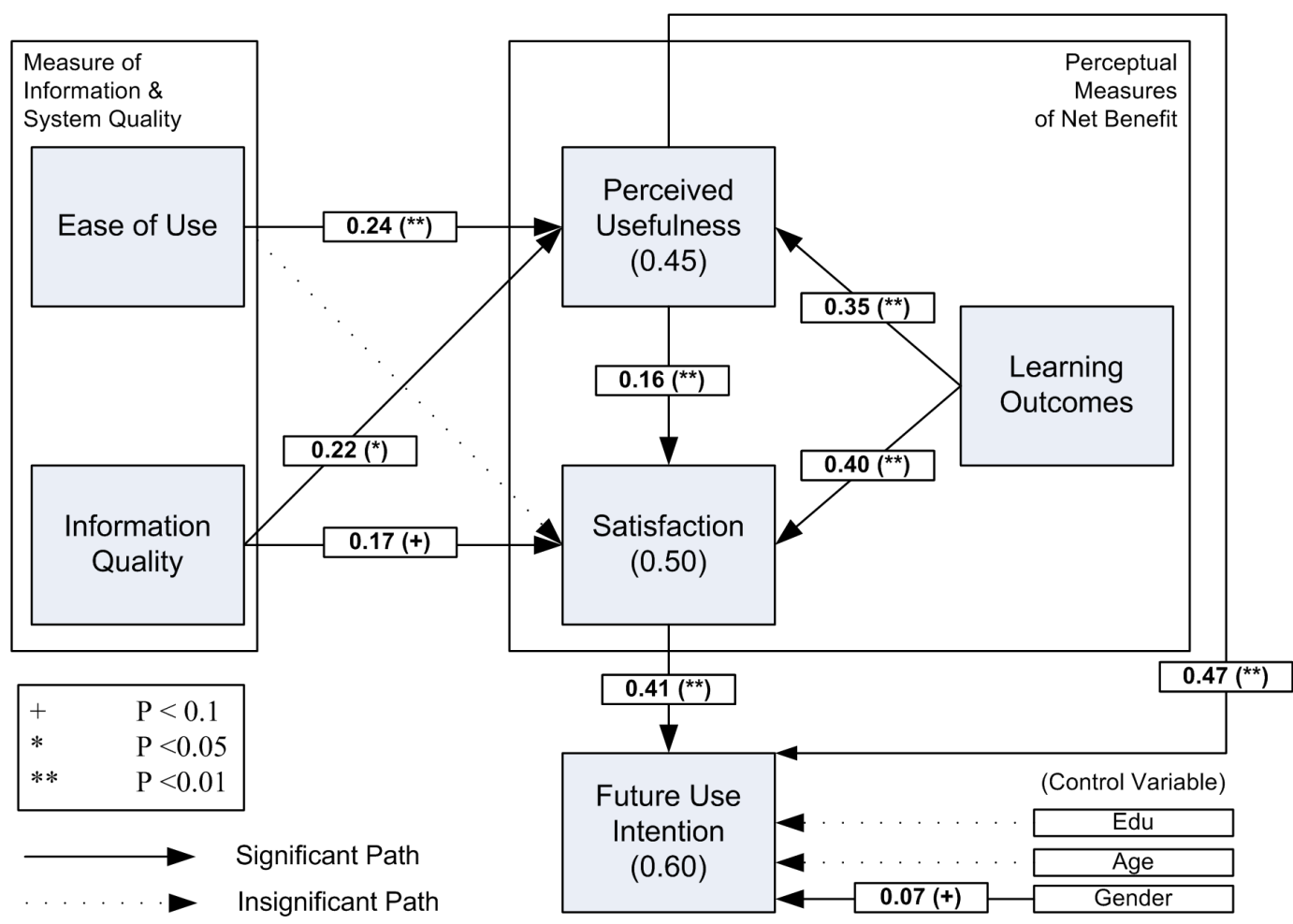

Figure 3: Structural Model of Instructor-Student Interactive Tools

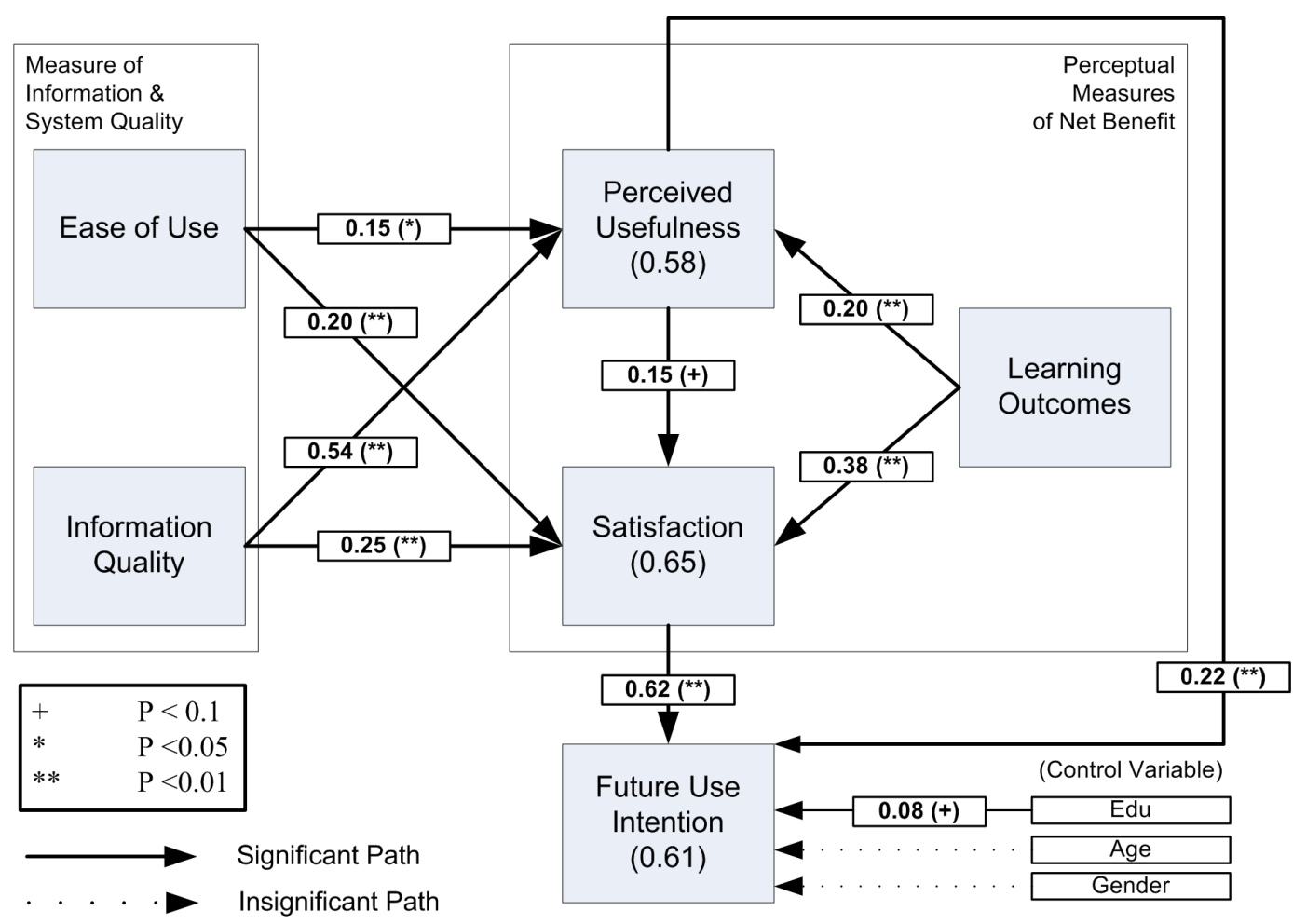


Table 1: Confirmatory Factor Analysis and Reliability Scoring

\begin{tabular}{|l|r|r|r|r|r|}
\hline $\begin{array}{r}\text { Construct (Cronbach's } \\
\text { alpha) }\end{array}$ & $\begin{array}{c}\text { IQ } \\
(0.841)\end{array}$ & $\begin{array}{c}\text { PEOU } \\
(0.889)\end{array}$ & $\begin{array}{c}\text { PU } \\
(0.897)\end{array}$ & $\begin{array}{c}\text { SAT } \\
(0.875)\end{array}$ & $\begin{array}{c}\text { BI } \\
(0.872)\end{array}$ \\
\hline IQ1 & $\mathbf{0 . 5 9 5}$ & 0.118 & 0.382 & 0.284 & 0.077 \\
\hline IQ2 & $\mathbf{0 . 7 9 2}$ & 0.058 & -0.044 & 0.261 & -0.078 \\
\hline IQ3 & $\mathbf{0 . 5 9 2}$ & 0.005 & 0.102 & 0.203 & 0.042 \\
\hline IQ4 & $\mathbf{0 . 7 6 6}$ & 0.191 & 0.189 & 0.159 & 0.229 \\
\hline IQ5 & $\mathbf{0 . 7 1 0}$ & 0.150 & -0.023 & -0.044 & 0.300 \\
\hline IQ6 & $\mathbf{0 . 7 8 4}$ & 0.350 & 0.009 & -0.082 & 0.201 \\
\hline PEOU1 & 0.099 & $\mathbf{0 . 8 3 2}$ & 0.036 & 0.210 & 0.018 \\
\hline PEOU2 & 0.151 & $\mathbf{0 . 7 8 6}$ & 0.055 & -0.030 & 0.026 \\
\hline PEOU3 & 0.333 & $\mathbf{0 . 8 0 4}$ & 0.008 & -0.009 & 0.064 \\
\hline PEOU4 & 0.107 & $\mathbf{0 . 9 0 4}$ & 0.087 & 0.110 & 0.140 \\
\hline PU1 & 0.231 & 0.254 & 0.098 & $\mathbf{0 . 6 0 7}$ & 0.336 \\
\hline PU2 & 0.171 & -0.030 & 0.315 & $\mathbf{0 . 8 1 6}$ & 0.156 \\
\hline PU3 & 0.164 & 0.148 & 0.359 & $\mathbf{0 . 7 9 6}$ & 0.201 \\
\hline PU4 & 0.139 & 0.003 & 0.201 & $\mathbf{0 . 8 7 8}$ & 0.211 \\
\hline SAT1 & -0.056 & -0.051 & $\mathbf{0 . 8 3 9}$ & 0.320 & 0.089 \\
\hline SAT2 & 0.042 & -0.023 & $\mathbf{0 . 8 5 3}$ & 0.130 & -0.012 \\
\hline SAT3 & 0.258 & 0.205 & $\mathbf{0 . 7 4 3}$ & 0.060 & 0.205 \\
\hline SAT4 & 0.065 & 0.063 & $\mathbf{0 . 8 3 2}$ & 0.231 & 0.088 \\
\hline OL1 & 0.162 & -0.399 & 0.355 & 0.172 & 0.279 \\
\hline BI1 & -0.005 & 0.252 & 0.079 & 0.049 & $\mathbf{0 . 7 7 2}$ \\
\hline BI2 & 0.260 & -0.101 & 0.058 & 0.374 & $\mathbf{0 . 7 4 3}$ \\
\hline BI3 & 0.152 & -0.046 & 0.111 & 0.311 & $\mathbf{0 . 8 0 9}$ \\
\hline BI4 & 0.183 & 0.040 & 0.121 & 0.114 & $\mathbf{0 . 8 4 5}$ \\
\hline
\end{tabular}

a. IQ, PEOU, PU, SAT, BI stand for the information quality, perceived ease of use, perceived usefulness, satisfaction, and behavior intention to use in the future.

Table 2: Profile of Survey Respondents

\begin{tabular}{|c|c|c|}
\hline Tool Types & $\begin{array}{c}\text { Self-Paced } \\
\text { Mode }\end{array}$ & $\begin{array}{c}\text { Instructor-Student } \\
\text { Interactive Model }\end{array}$ \\
\hline Education Level & & 191 \\
\hline Under-graduate & 294 & 97 \\
\hline Post Graduate & 151 & 183 \\
\hline Age & & 50 \\
\hline $18-25$ & 291 & 37 \\
\hline $26-30$ & 61 & 16 \\
\hline $31-36$ & 44 & 6 \\
\hline $37-40$ & 18 & 178 \\
\hline$>41$ & 31 & 113 \\
\hline Gender & & \\
\hline Male & 232 & \\
\hline Female & 213 & \\
\hline & & \\
\hline
\end{tabular}


Table 3 Measurement Model Fit

\begin{tabular}{|l|c|c|c|}
\hline \multicolumn{1}{|c|}{ Fit Indices } & $\begin{array}{c}\text { Self-Paced } \\
\text { Mode }\end{array}$ & $\begin{array}{c}\text { Instructor-Student } \\
\text { Interactive Mode }\end{array}$ & $\begin{array}{c}\text { Desired } \\
\text { Levels }\end{array}$ \\
\hline$\chi 2$ / D.F. & 1.746 & 1.695 & $<3.0$ \\
\hline CFI & 0.975 & 0.968 & $>0.90$ \\
\hline TLI & 0.969 & 0.961 & $>0.90$ \\
\hline RMSEA & 0.041 & 0.049 & $<0.08$ \\
\hline Standardized RMR & 0.0293 & 0.0434 & $<0.08$ \\
\hline GFI & 0.946 & 0.923 & $>0.90$ \\
\hline AGFI & 0.928 & 0.897 & $>0.80$ \\
\hline
\end{tabular}

Table 4: Descriptive Statistics and Reliability of Constructs

\begin{tabular}{|l|c|c|}
\hline \multirow{2}{*}{ Construct(a) } & $\begin{array}{c}\text { Self-Paced } \\
\text { E-Learning Mode }\end{array}$ & $\begin{array}{c}\text { Instructor-student } \\
\text { Interactive Mode }\end{array}$ \\
\cline { 2 - 3 } & Mean (S.D.) & Mean (S.D.) \\
\hline Information Quality (5) & $3.46(0.56)$ & $3.55(0.59)$ \\
\hline PEOU (3) & $3.46(0.63)$ & $3.61(0.62)$ \\
\hline Perceived Usefulness (4) & $3.39(0.65)$ & $3.53(0.66)$ \\
\hline Satisfaction (3) & $3.23(0.66)$ & $3.48(0.76)$ \\
\hline Learning Performance (1) & $3.05(0.79)$ & $3.23(0.82)$ \\
\hline Behavioral Intention (4) & $3.40(0.68)$ & $3.53(0.69)$ \\
\hline
\end{tabular}

a. The number in parentheses indicates the resulting number of items in the scale.

Table 5: Squared Correlations, Reliability, and Average Variance Extracted

\begin{tabular}{|l|c|c|c|c|c|c|c|c|c|c|c|c|c|}
\hline & \multicolumn{3}{|c|}{ Self-Paced E-Learning Mode } & \multicolumn{3}{c|}{ Instructor-Student Interactive Mode } \\
\hline & IQ & SQ & PU & SAT & LO & BI & & IQ & SQ & PU & SAT & LO & BI \\
\hline IQ & $\mathbf{0 . 5 1}$ & & & & & & & $\mathbf{0 . 5 1}$ & & & & & \\
\hline SQ (PEOU) & 0.36 & $\mathbf{0 . 6 0}$ & & & & & & 0.21 & $\mathbf{0 . 6 2}$ & & & & \\
\hline PU & 0.22 & 0.21 & $\mathbf{0 . 6 4}$ & & & & & 0.40 & 0.20 & $\mathbf{0 . 6 6}$ & & & \\
\hline SAT & 0.19 & 0.16 & 0.20 & $\mathbf{0 . 5 6}$ & & & & 0.32 & 0.20 & 0.33 & $\mathbf{0 . 6 2}$ & & \\
\hline LO & 0.13 & 0.08 & 0.19 & 0.21 & N.A. & & & 0.21 & 0.16 & 0.24 & 0.43 & N.A. & \\
\hline BI & 0.26 & 0.23 & 0.36 & 0.28 & 0.19 & $\mathbf{0 . 6 3}$ & & 0.33 & 0.25 & 0.30 & 0.40 & 0.26 & $\mathbf{0 . 6 4}$ \\
\hline Reliability & 0.82 & 0.82 & 0.88 & 0.78 & N.A. & 0.87 & & 0.82 & 0.82 & 0.88 & 0.83 & N.A. & 0.87 \\
\hline C.R. & 0.82 & 0.82 & 0.88 & 0.79 & N.A. & 0.87 & & 0.82 & 0.83 & 0.88 & 0.83 & N.A. & 0.87 \\
\hline AVE & 0.51 & 0.60 & 0.64 & 0.56 & N.A. & 0.63 & & 0.51 & 0.62 & 0.66 & 0.62 & N.A. & 0.64 \\
\hline
\end{tabular}

Diagonal values represent the square root of average variance extracted (AVE), and off-diagonal elements are the zero-order correlations among constructs. For discriminant validity, diagonal elements should be larger than offdiagonal elements.

Table 6: Structural Model Fit

\begin{tabular}{|l|c|c|c|}
\hline \multicolumn{1}{|c|}{ Fit Indices } & $\begin{array}{c}\text { Self-Paced } \\
\text { Mode }\end{array}$ & $\begin{array}{c}\text { Instructor-Student } \\
\text { Interactive Mode }\end{array}$ & $\begin{array}{c}\text { Desired } \\
\text { Levels }\end{array}$ \\
\hline$\chi 2$ / D.F. & 1.902 & 1.751 & $<3.0$ \\
\hline CFI & 0.959 & 0.963 & $>0.90$ \\
\hline TLI & 0.950 & 0.956 & $>0.90$ \\
\hline RMSEA & 0.045 & 0.051 & $<0.08$ \\
\hline Standardized RMR & 0.0406 & 0.0488 & $<0.08$ \\
\hline GFI & 0.931 & 0.917 & $>0.90$ \\
\hline AGFI & $0.908 h$ & 0.891 & $>0.80$ \\
\hline
\end{tabular}


Table 7: Measurement Invariance Analysis

\begin{tabular}{|l|l|l|l|l|}
\hline $\begin{array}{l}\text { Goodness of } \\
\text { Fit Indices }\end{array}$ & $\begin{array}{l}\text { Configural } \\
\text { Invariance }\end{array}$ & $\begin{array}{l}\text { Metric } \\
\text { Invariance }\end{array}$ & $\begin{array}{l}\text { Scalar } \\
\text { Invariance }\end{array}$ & $\begin{array}{l}\text { Desired } \\
\text { Level }\end{array}$ \\
\hline $\mathrm{X}^{2} / \mathrm{D} . \mathrm{F}$. & 1.689 & 1.672 & 1.701 & $<5$ \\
\hline $\mathrm{TLI}$ & 0.966 & 0.967 & 0.971 & $>0.9$ \\
\hline CFI & $\mathbf{0 . 9 7 2}$ & $\mathbf{0 . 9 7 1}$ & $\mathbf{0 . 9 6 8}$ & $>0.9$ \\
\hline SRMR & 0.0288 & 0.0329 & 0.0346 & $<0.08$ \\
\hline RMSEA & 0.030 & 0.030 & 0.031 & $<0.08$ \\
\hline
\end{tabular}

Table 8: Mean Comparison of Latent Constructs across Groups

\begin{tabular}{|l|c|c|c|c|}
\hline Constructs & $\begin{array}{c}\text { Self-Paced } \\
\text { E-Learning Mode }\end{array}$ & & $\begin{array}{c}\text { Instructor-student } \\
\text { Interactive Mode }\end{array}$ & $\begin{array}{c}\text { Support } \\
\text { Hypothesis? }\end{array}$ \\
\hline System Quality & $-0.266^{* *}$ & $<$ & 0 & No hypothesis \\
\hline Information Quality & $-0.174^{* *}$ & $<$ & 0 & $\mathrm{H} 1$ (inconclusive) \\
\hline Perceived Usefulness & $-0.243^{* *}$ & $<$ & 0 & $\mathrm{H} 2(\sqrt{ })$ \\
\hline Learning Outcomes & $-0.302^{* *}$ & $<$ & 0 & $\mathrm{H} 3(\sqrt{ })$ \\
\hline Satisfaction & $-0.384^{* *}$ & $<$ & 0 & $\mathrm{H} 4(\sqrt{ })$ \\
\hline Behavioral Intention & $-0.190^{* *}$ & $<$ & 0 & No hypothesis \\
\hline
\end{tabular}

Table 9: Testing Alternative Explanations of Mean Differences

\begin{tabular}{|c|c|c|c|c|c|c|}
\hline & \multicolumn{2}{|c|}{ Gender Effect } & \multicolumn{2}{|c|}{ Education Effect } & \multicolumn{2}{|c|}{ Age Effect } \\
\hline $\begin{array}{l}\text { Subject } \\
\text { Construct }\end{array}$ & $\begin{array}{l}\text { SP Male } \\
\text { vs. } \\
\text { ISI Male }\end{array}$ & $\begin{array}{l}\text { SP Female } \\
\text { vs. } \\
\text { ISI Female }\end{array}$ & $\begin{array}{l}\text { SP Under } \\
\text { vs. } \\
\text { ISI Under }\end{array}$ & $\begin{array}{c}\text { SP Graduate } \\
\text { vs. } \\
\text { ISI Graduate }\end{array}$ & $\begin{array}{c}S P<=25 \\
\text { vs. } \\
|S|<=25\end{array}$ & $\begin{array}{c}\mathrm{SP}>25 \\
\text { Vs. } \\
|\mathrm{SI}|>25\end{array}$ \\
\hline $\begin{array}{l}\text { System } \\
\text { Quality }\end{array}$ & $\mathrm{SP}<\mathrm{ISI}$ & \multirow{6}{*}{$\begin{array}{l}\text { Insufficient } \\
\text { sample } \\
\text { size for } \\
\text { multi-group } \\
\text { mean } \\
\text { comparison } \\
\text { via SEM }\end{array}$} & $\mathrm{SP}<\mathrm{ISI}$ & \multirow{6}{*}{$\begin{array}{l}\text { Insufficient } \\
\text { sample } \\
\text { size for } \\
\text { multi-group } \\
\text { mean } \\
\text { comparison } \\
\text { via SEM }\end{array}$} & $\mathrm{SP}<\mathrm{ISI}$ & \multirow{6}{*}{$\begin{array}{l}\text { Insufficient } \\
\text { sample } \\
\text { size for } \\
\text { multi-group } \\
\text { mean } \\
\text { comparison } \\
\text { via SEM }\end{array}$} \\
\hline $\begin{array}{l}\text { Information } \\
\text { Quality }\end{array}$ & $\mathrm{SP}<\mathrm{ISI}$ & & $\underline{S P}=|S|$ & & $\underline{S P=I S I}$ & \\
\hline $\begin{array}{l}\text { Perceived } \\
\text { Usefulness }\end{array}$ & $\mathrm{SP}<\mathrm{ISI}$ & & $\mathrm{SP}<\mathrm{ISI}$ & & $\mathrm{SP}<\mathrm{ISI}$ & \\
\hline $\begin{array}{l}\text { Learning } \\
\text { Outcomes }\end{array}$ & $\mathrm{SP}<\mathrm{ISI}$ & & $\mathrm{SP}<\mathrm{ISI}$ & & $\mathrm{SP}<\mathrm{ISI}$ & \\
\hline Satisfaction & $\mathrm{SP}<\mathrm{ISI}$ & & $\mathrm{SP}<\mathrm{ISI}$ & & $\mathrm{SP}<\mathrm{ISI}$ & \\
\hline $\begin{array}{l}\text { Behavioral } \\
\text { Intention }\end{array}$ & $S P<I S I$ & & $S P<I S I$ & & $S P<I S I$ & \\
\hline
\end{tabular}

